\title{
Editorial
}

\section{Triage is easy, said no triage nurse ever}

\section{Enrico Dippenaar, MSc*}

edippenaar@mweb.co.za

Stevan Bruijns, $\mathrm{PhD}$

Division of Emergency Medicine, University of Cape Town, South Africa

${ }^{*}$ Corresponding author.

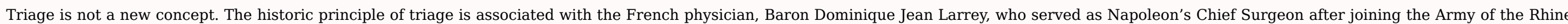

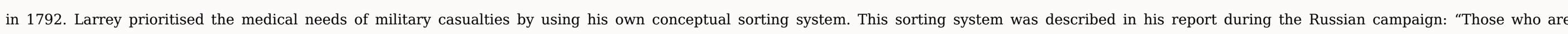

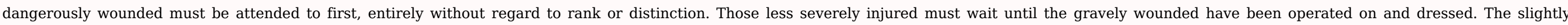

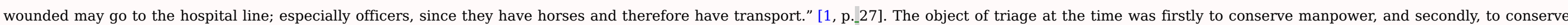

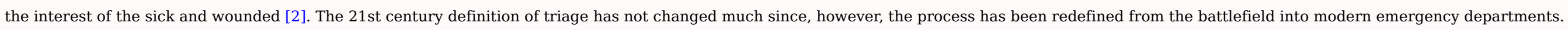

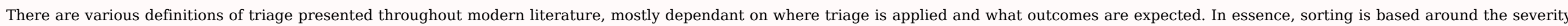

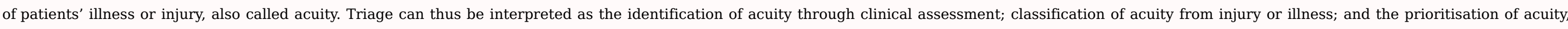
based on appropriate treatment and medical care required.

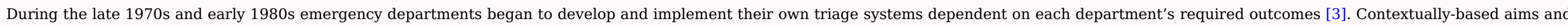

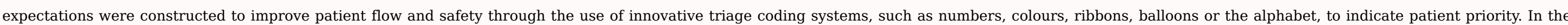

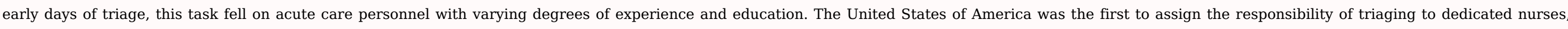
eventually formalising emergency triage as a sub-speciality of emergency nursing. This trend was soon followed in Australia, Canada and the United Kingdom.

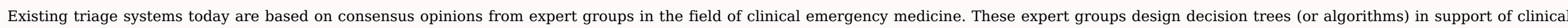

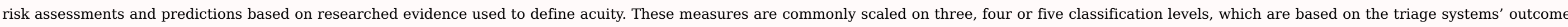

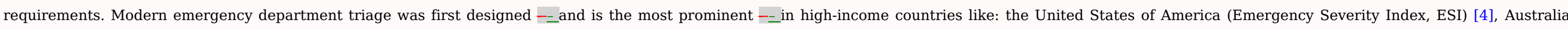

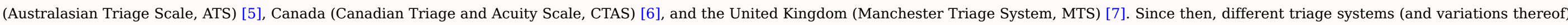

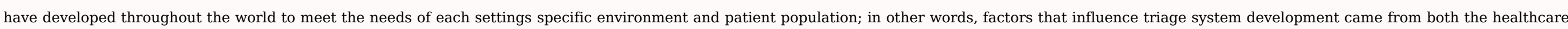
provider's and service user's perspectives.

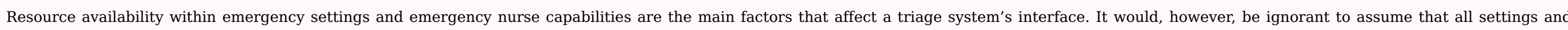

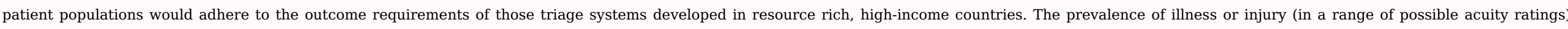

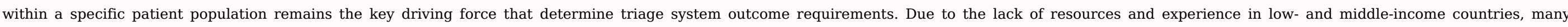

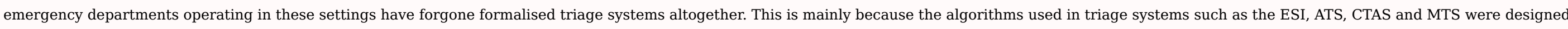

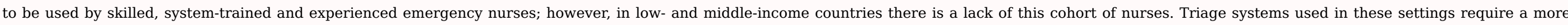

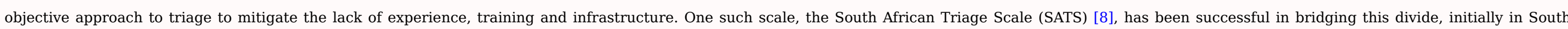

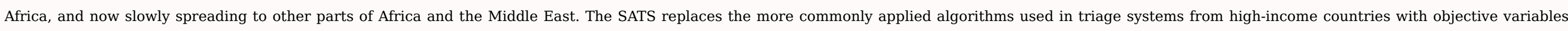
that are largely based on a patient's vital signs and a manageable list of clinical descriptors.

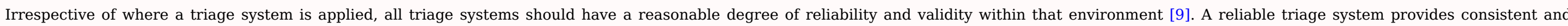




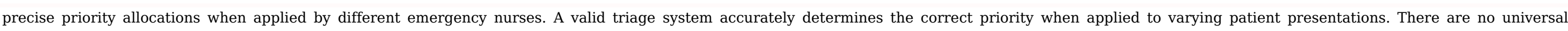

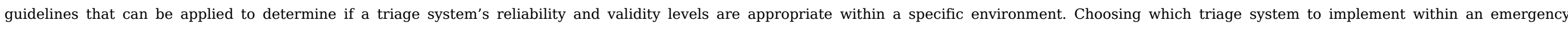

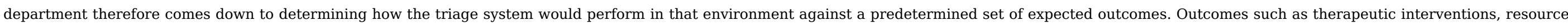

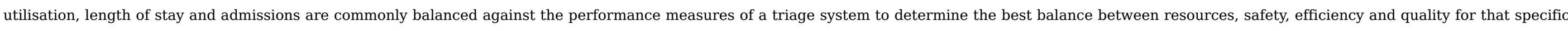

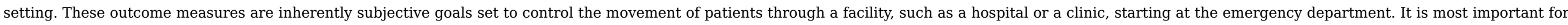
any triage system to recognise and determine patient acuity along these predetermined goals and balances so that appropriate resources can be allocated within a reasonable timeframe.

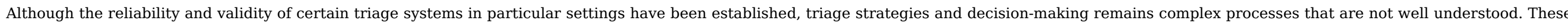

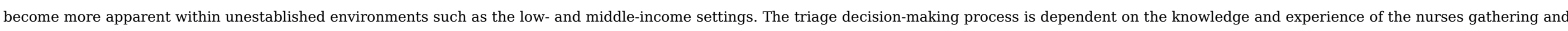

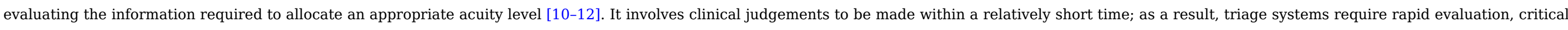

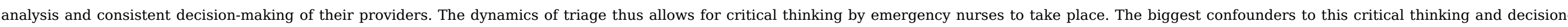

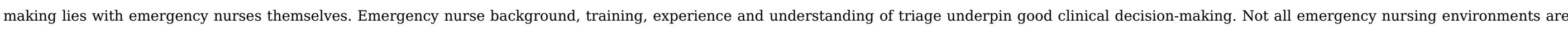

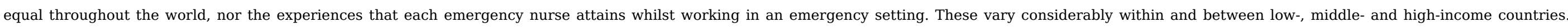

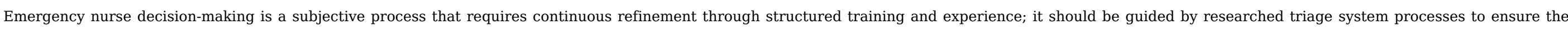

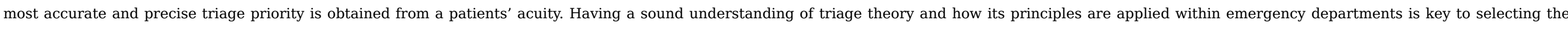
most appropriate triage system for any given setting.

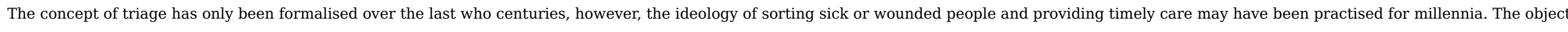

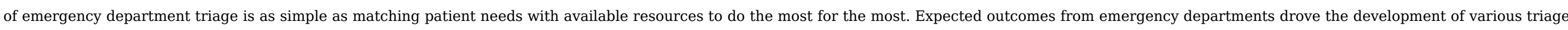

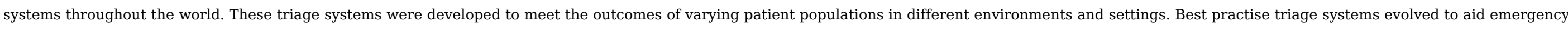

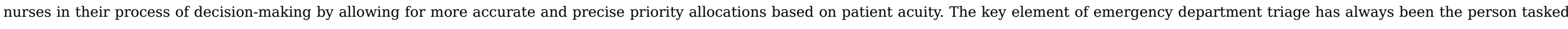

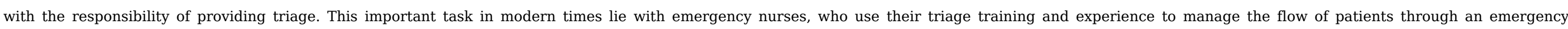
department.

\section{References}

[1] D.J. Larry, The surgical memoirs of the campaign in Russia, 1832, J Mercer; Philadelphia, 27.

[2] A.D. Tuttle, Handbook for the medical soldier, 1927, William Wood and Company; New York, 84-85.

[3] M. Fry and G. Burr, Review of the triage literature: past, present, future?, Aust Emerg Nurs J 5 (2), 2002, 33-38.

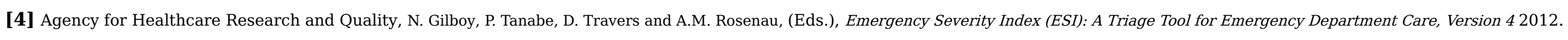

[5] Australasian Government Department of Health and Ageing, M.F. Gerdtz, J. Considine, N. Sands, C.J. Stewart, D. Crellin and W.E. Pollock, (Eds.), Emergency Triage Education Kit 2009.

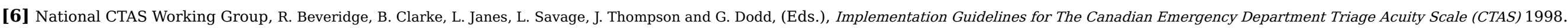

[7] Manchester Triage Group, 2nd ed., K. Mackway-Jones, J. Marsden and J. Windle, (Eds.), Emergency Triage 2006.

[8] South African Triage Group, B. Cheema and M. Twomey, (Eds.), The South African Triage Scale (SATS) 2012, editors.

[9] H.A. Moll, Challenges in the validation of triage systems at emergency departments, J Clin Epidemiol 63 (4), 2010, 384-388.

[10] A. Smith, Using a theory to understand triage decision making, Int Emerg Nurs 21 (2), 2013, 113-117.

[11] G. Reay and J.A. Rankin, The application of theory to triage decision-making, Int Emerg Nurs 21 (2), 2013, 97-102. 
[12] A.J. Noon, The cognitive processes underpinning clinical decision in triage assessment: a theoretical conundrum?, Int Emerg Nurs 22 (1), 2014 , $40-46$. 